\title{
Research on Space and Operation for Non-Profit Organization to Participate in Community Aged Care Service in China
}

\author{
Le PEI \\ Management College \\ Bohai University \\ Jinzhou, China \\ P982262@126.com
}

\begin{abstract}
The purpose of this research is to explore effective operation mode for non-profit organization to participate and provide aged care service in modern Chinese society. The aged society needs huge amount aged care services, especially in local community. The government and market have their limit. So, the non-profit organization get chance to develop in community aged care service. The analysis demonstrates plenty space from theory, policy and practice in community aged care service. The stakeholders include government, community, service object, and non-profit organization. Their roles and interests are considered. The non-profit organization is vital to society as the third sector, which has different resource, behavior style and influence. The social security and welfare may be improved through its participation in aged care service. This research provides a solution of operation mode for non-profit organization in China from action design to evaluation and motivation to ensure performance of community aged care service.
\end{abstract}

Keywords-aged care service; community; non-profit organization; social security; social welfare

\section{INTRODUCTION}

The policy of family planning in China controlled the growth of population, and caused the family structure of "4-21 ”. There are massive study and employment in different places and emigration that accelerate population mobility than ever before. New mode should be probed in new normal to remedy family and social aged care. As a vital actor of social services, non-profit organization could and should play more basic roles in community aged care service.

\section{THE SPACE FOR NON-PROFIT ORgANIZATION TO PARTICIPATE IN COMMUNITY AGED CARE SERVICE}

The amount of old people received community aged care service is more than 95\% in Japan, the United States and the United Kingdom. In community, the local resources are easy to use, the expenditure is low, the situation is familiar, and the social network is sustained. Then, the old people can live independently longer. (In Chinese) [1] The industry of aged care service in China lags behind developed countries, and the coverage and strength of social security is inefficient. So, the third force should be used adequately besides government and market.

\section{A. Theoretical Space}

The welfare pluralism considered that government is not the only provider of social welfare. The market, non-profit organization, family and community have their roles. Nonprofit organizations increase social welfare by decentralization and participation. Government may permit non-profit organizations to make decision partly in aged care service of social security. Non-profit organizations take part in community aged care service directly and indirectly. Their functions include security sponsor, health care, spiritual consolation, education and entertainment, and so on. Nonprofit organizations pay more attention to the poor and disadvantaged groups and public welfare. That is benefit to maintain social justice and to enhance social value and network of the old people.

Non-profit organizations consist of the third sector, which is independent of public sector and private sector. It prevents government failure and market failure in community aged care service by reducing gamble, corruption, maltreatment, and harm. The government may use principal agent, PPP, and so on, to transfer part social security role to non-profit organizations. It is a way of social governance that non-profit organizations improve quality of community aged care service. More resources are better to the quality and efficiency of aged care service, the social satisfaction and sense of gain will be increased. That non-profit organizations serve in local community will also reduce conflict between government and voters.

\section{B. Policy Space}

The policy support accelerates the socialization of community aged care service. There are more actors, services and possibility than before. The non-profit organization management and development policies include Regulations on the Registration and Administration of Social Organizations, Provisional Regulations on the Registration and Administration of Private Non-Enterprise Units, Interim Measures for the Registration of Private Non-Enterprise Units, Foundation Management Ordinance, etc. The special provisions include 
Measures for the Administration of Income Tax Collection of Public Institutions, Social Organizations, and Private NonEnterprise Units, etc.

The policies to improve and speed up community aged care service include "12th Five-Year" Planning of China's Aging Industry Development, Construction Planning of Social Pension Service System, Decision on Strengthening the Ageing Work, Notice on Accelerating the Development of Pension Service Industry, Guides on Promoting the Evaluation Work of the Aged Care Service, Law on the Protection of the Rights and Interests of the Elderly, etc.

\section{Practical Space}

Since 1999, the aging situation is increasingly serious, for the old population base is large, the growth is fast, and the empty nested phenomenon is universal. By the end of 2015, the old population over 60 is 222,000,000 and $16.1 \%$, the old population over 65 is $143,860,000$ and $10.5 \%$. There are many vulnerable old people, such as disabled and semi-disabled old people, dementia and semi-dementia old people, and emptynested old people. It is predicted that the old population over 60 will be $243,000,000$ and $18 \%$ by 2020 . Under the influence of traditional culture, lifestyle and living cost, many old people are reluctant to leave familiar community to receive aged care service in pension agency. Thus, that flexible, personal, humanistic, family lifestyle community aged care service is necessary. Non-profit organizations should provide plentiful aged care service combination, which connects person, family, community and society. They can take advantage of humanity, region and relationship to shorten the distance with old people in space and psychology.

That daycare center, elderly meal service, door-to-door distribution of necessities of life, house cleaning, home medical care are needed generally by old people who lived in community. (In Chinese) [2] The local government, community and non-profit organization work together, and get positive outcome. Shanghai government purchases community aged care service from non-profit organizations to assist the old people in food, clean, out of home, shower, medical care, emergency, and so on. The " $3+X$ " community aged care system was built in Beijing, which means that government, non-profit organization and community residents cooperate in aged care service projects. In Guangzhou, community aged care resource combined with local medical and health care resource, and the old people may receive aged care service valued 200-400 Yuan according to their viability and economic income. (In Chinese) [3]

\section{THE OPERATION FOR NON-PROFIT ORGANIZATION TO Participate In COMMUnity Aged CARE SERVICE}

Before operation, non-profit organizations should orientate precisely. The content and method of aged care service should be improved. The relationship among government, community, service object, and non-profit organization should be handled properly. The government support and supervise the operation through policies to guarantee the rationality and justice. The community offers infrastructure and place, which will impact the service time, location, scope, mode and result. The service object proposes demands in neighborhood care, emotional resource, habit, relationship, lifestyle and culture.

In practice, the developed countries have positive experience. There are Elderly Welfare Law, Elderly Health Care Law, 10 Year Strategic Plan for the Promotion of Health Benefits for the Elderly in Japan. The government, non-profit organizations and volunteers built multivariate community aged care service system. The services include nursing care, home care and health care. There are Old Age Act, Elderly Community Service Employment Act and Elderly Volunteer Work Program to provide pension, subsidy and investment plan to old people in the United States. The elderly community is consists of selfcare community, assisted living community, sustained care retirement community and special care community. There are National Health Service and Community Care Act, Elderly Care White Paper in the United Kingdom. The government subsidizes private and non-profit organizations to provide community aged care services. The service is divided into care in community and care by community.

In China, the main participation channels for non-profit organizations are public services purchase, cooperation with community, independent activity, and cooperation with enterprise. The first two channels are guaranteed by finance and policy, especially in purchase contract of aged care service. In those, social groups focus on mediation and propaganda, people-run non-enterprise unites focus on specialization and demonstration, funds focus on endowment, fund-raising and assist supporting. In smart cities, internet + technology should be used to optimize service process and build community aged care service platform, information and call system and virtual community. On the base of information safety, aged care service files should be recorded to make service pertinently and effectively, which include information of healthy, education, demand, living and economic condition. The advanced technologies should be adopted to simplify operation, reinforce maintenance and improvement.

The service forms of non-profit organization include home care, community care center, and daily service and emergency response volunteer center. The non-profit organizations should provide one-stop services independently or jointly, which include daily home care, housekeeping, community canteen, emergency response, health care and disease prevention, entertainment and psychological counseling, leisure and skill learning, legal consultation and protection of rights and interests. The charge is only to compensate cost. The facilities and rooms in community can be used or rented. The location may be near hospital, medical service or rehabilitation center. (In Chinese) [4] The community facilities in Jiangsu are in urban and rural construction plans. The community aged care service centers are subsidized by government in Dalian. (In Chinese) [5] These facilities must comply with relevant norms and standards to be convenient to the old people.

Full-time staffs, part-time staffs and volunteers should be recruited. Skill training and human resources development will improve their attitude, quality and professionalization. College students, especially those major in social work, medicine, psychology, household management, public management, should be encouraged to work in community aged care service. 
The old people resource should be developed deeply that convert aged demographic dividend into real profit in consume, investment, knowledge and technique. The time bank created by Edgar Kahn is based on voluntary service. The volunteers store service time in this bank and get same service time for free when need. They may service better for their aged care service demands.

\section{The EVAluation AND Motivation On Non-Profit ORgANIZATION TO PARTICIPATE IN COMMUNITY AGED CARE SERVICE}

The idleness, misapplication, corruption will arise, if there is no evaluation and motivation on non-profit organizations. An integrative evaluation and motivation system must cover whole process and all related actors. That rights, obligations, criterion, procedure, openness and transparence should be specified to make evaluation objectively and precisely. According to subject, it includes: 1 . Government and community evaluation, which evaluates identity of non-profit organization, legality of activity, approval of service project. 2. Service object evaluation, which evaluates service result from sense of security and happiness. 3. Self-evaluation, which evaluates work of organization and members, performance of service activities, effect of project. 4. Social evaluation, which evaluates different aspects by the public, media, and the third party. According to content, it includes: 1 . Standard evaluation, which evaluates organization structure, staffs, management, development plan, financial regulation and service criteria. 2. Effect evaluation, which evaluates constitution, quality and convenience of service, and amount, structure and feedback of beneficiaries. 3. Efficiency evaluation, which evaluates cost, benefit, responsiveness, timeliness. 4. Process evaluation, which evaluates legitimacy, justice, rationality. There are indicators as Health and Welfare Criterion of the Elderly made by ministry of health and welfare of Japan, Guidelines for the Evaluation of Livable Communities made by AARP in the United States, and BHCAA made by the United States environmental protection agency.(In Chinese)[6]

The government, community and industry association together examine the registration and Qualification of nonprofit organizations. The entry restrictions should be loosed, while process control should be strengthened. The effect and efficiency are focuses. The old people will manage community aged care service through community affairs council, which supervise and evaluate services and non-profit organizations with community. The non-profit organizations must be classified and graded. The ranking should be provided to the public, which will be the reference to public service purchase and public project. The reward and punishment mechanism should be built, the excellent will get support, while the unqualified will be punished or forced to quit. The service procedure, inner governance structure and project operation of non-profit organization should be optimized. Finance management and audit should be adopted to improve transparence and openness of operation. According to qualification certification and service standard, the staffs and volunteers should be trained systematically.

To gain steady and sustained effect, motivation combination should be designed and implemented. The comprehensive motivation system will excite non-profit organizations. 1. That policy motivation includes: combining non-profit organization participating in community aged care service with social development planning, improving management policies and measures, supplying basic support. 2. That material motivation includes: resource allocation should be leaned to major projects, excellent non-profit organization or those need help, such as finance, subsidy, or project cooperation. 3. That propaganda motivation includes: showing non-profit organizations, service activities and project on internet, TV, broadcast, newspaper, magazine and meeting, especially official background media. On the one hand, it is a kind of supervision. On the other hand, non-profit organization may get more social resource, such as understanding of the public, professional management guidance, private and enterprise donate. The connection of community aged care service of non-profit organization and social security will bring more positive social effect and promote the sense of gain and satisfaction of the old people in China.

\section{SUMMARY}

There is a tendency of various and complex aged care will in modern society. Besides basic physiological needs, the aged population has more emotional and spiritual needs. Now, in China, the social security is limited, and the aged care industry is undeveloped. So, the mode of aged care service should be probed to adapt to new situation. It is a positive and beneficial solution that non-profit organizations utilize their own advantages to participate in community aged care service. There are theoretical space, policy space and practical space for non-profit organizations to provide aged care service in communities. But, the operation should be designed carefully and carried out steadily. To gain expected results, the total process should be evaluated and motivated effectively by different actors.

In any country, the aged care is a vital problem that should be solved properly. As a nature process, the old people are not the social burden, but a kind of important power and resource, which will bring knowledge and wealth to improve the whole society. The industry of aged care service is not mature in China, but treated seriously by all actors now. The development of industry and participation of non-profit organizations is designed in the $13^{\text {th }}$ five-year plan. It is not only a chance to grasp, but also a challenge to respond. The non-profit organizations should work together with other actors in community aged care service under the same goal of providing better service to meet the needs of society and the old people in China. In this research, the sphere of community aged care service is probed deeply, the actors and their interests are considered totally, the action solution is provided to nonprofit organizations in China systematically. It can be predicted that non-profit organization will get more and more incentive from government and society, and promote rapid development of community aged care service in China.

\section{ACKNOWLEDGMENT}

Thanks Shu Li, Qizhen Pei and other friends, for the helps and supports to finish this research and writing. The discussion with them is inspiring and constructive. 


\section{REFERENCES}

[1] WANG Cheng-hui, The Exploration and Inspiration of Communitybased Aging Pattern in USA, Research on Modern Cities [J].August 2012, pp. 35-44.

[2] CAI Zhonghua, AN Tingting, HOU Aoyu, Characteristics and Countermeasures for Community Elder Care Services Demand of the Urban Elderly, Social Security Studies [J].April 2013, pp. 45-49.

[3] Zhao Xiaoshi, Yu Dachuan, Discussion of the Problems in Guangzhou Community Pension, Reformation \& Strategy [J].July 2015, pp. 179-183.
[4] WANG Li-li, YANG Xiao-qi, DONG Peng-tao, The Development Status Quo Analysis of Urban Community Old-age Care Service Industry, Scientific Research on Aging [J].March 2014, pp. 29-36.

[5] Shao Wen-juan, Xi Wei-dong, Analysis on Operation status of Chinese Community Aged Care Institutions, Social Welfare [J].January 2015, pp. 46-49.

[6] Wang Xiaorong, Jia Weiyang, Investigation on Real Status of Community Retirement \& Primary Exploration on Satisfaction Evaluation Index for it, Journal of Architecture [J].December 2014, pp. 157-159. 